DOI: 1. 10.19195/0137-1150.163.21

\author{
ILARIA REMONATO \\ Universitá di Verona, Włochy \\ ilaria.remonato_01@univr.it
}

\title{
Некоторые наблюдения, касающиеся образа старости в творчестве Валентина Распутина
}

\author{
Человек стареет не тогда, \\ когда он доживает до старости, \\ а когда перестаёт быть ребёнком.
}

В. Распутин, Уроки франиузского, 1973

Образ старости и размышления о смысле последнего периода человеческой жизни играют важную роль в прозе Валентина Распутина (1937-2015). На наш взгляд, цитата в эпиграфе из рассказа Уроки франиузского (1973) очень ярко выражает его отношение к старости. В центре анализа данного доклада - духовный и психологический облик пожилых персонажей тематика, которая проходит красной нитью через все произведения недавно скончавшегося автора. Старость является постоянной, сквозной темой в его творчестве, и именно значительность этого мотива ${ }^{1}$ даёт нам возможность проанализировать разные модальности его художественного изображения. В настоящей статье мы обратимся преимущественно к повестям Последний срок (1970) и Прощание с Матёрой (1976), в которых старики занимают главное место. Присутствие общих черт в трактовке интересующего нас вопроса позволяет также провести некоторые параллели с рассказами $\mathrm{Ba}$ силий и Василиса (1966) и Женский разговор (1995).

Как известно, детство, проведенное в Юго-Восточной Сибири, сильно повлияло на писателя. Деревенское происхождение имело большое значе-

${ }^{1}$ O разных современных философских и социологических представлениях понятия старости см., напр., M. Augé, Une ethnologie de soi. Le temps sans âge, Paris 2014; S. Tramma, Inventare la vecchiaia, Roma 2000 и Е. Spedicato Iengo, Senilità e dintorni, Lanciano 2003. 
ние в развитии его мировоззрения, и в основу его прозы легли жизнь и конкретные проблемы деревни. Распутин использует основные темы и некоторые стилистические средства, свойственные и другим представителям так называемой „деревенской прозы”2, таким как Виктор Астафьев, Федор Абрамов и Василий Белов. Несмотря на сходство тематики, распутинские произведения из-за масштаба их философского содержания выходят за рамки этого литературного направления, принимая универсальное, общечеловеческое значение. Иными словами, действие большинства повестей автора происходит в сибирской деревне, но, в то же время, на его страницах ставятся вечные вопросы бытия. Распутин постоянно исследует духовный мир обыкновенного человека, изображая его сомнения и переживания в период социальных и экономических изменений, происходящих в советском обществе брежневской эпохи (имеется в виду индустрализация и модернизация страны, развитие туризма, научно-техническая революция и подобные феномены). Можно сказать, что в каждом поступке распутинских героев раскрывается их человеческая сущность. Как пишет Владимир Филиппов, этот писатель „как никто другой, умеет придать конкретному факту социальной или бытовой жизни обобщающий, символический смысл. Правда творчества, по его мнению, должна вытекать как родник из земли, из народной нравственности" "3. Не случайно, хранительницами народной нравственности на страницах писателя выступают часто старухи.

Сюжет повести Последний срок развивается вокруг фигуры пожилой крестьянки Анны. События происходят в 1960-х годах в сибирской тайге недалеко от реки Ангары, между Иркутском и Братском. Наступает осень. После лета старуха Анна изнемогла, слегла и ожидает смерти:

Старуха Анна лежала на узкой железной кровати возле русской печки и дожидалась смерти, время для которой вроде приспело: старухе было под восемьдесят ${ }^{4}$.

Умирающая Анна спокойно готовится к концу своего земного времени. Она простая женщина из народа и считает, что уже много прожила. Старуха смотрит на смерть как на естественное событие: она находится на грани небытия, и в этот её последний срок с ней уже ничего из ряда вон выходящего случиться не может. Писатель воссоздает процесс затянувшегося умирания с редким, почти толстовским тактом; вообще мотив смерти играет важную роль в произведениях автора и часто связывается с изображением поминаль-

2 Подробнее об этом см., среди прочих, А. Большакова, Русская деревенская проза XX века: код прочтения, Шумен 2002, с. 101-114; А. Большакова, Нация и менталитет: феномен «деревенской прозы» XX века, Москва 2000 и В. Недзвецкий, В. Филиппов, Русская «деревенская проза», Москва 2002, с. 128-142.

3 В. Недзвецкий, В. Филиппов, Русская..., с. 129.

${ }^{4}$ В. Распутин, Последний срок, [в:] idem, Избранные произведения в 2-х томах, т. 1, Москва 1984, с. 128. 
но-погребальных обрядов 5 . В психологическое описание пожилой женщины включены символические черты, которые имеют значительное сходство с внутренними качествами прототипической модели старой крестьянки в русской „деревенской литературе”, т.е. с образом Матрёны в знаменитой повести Александра Солженицына Матрёнин двор (1963). Так же, как и Матрёна, распутинская Анна Степановна оказывается скромным, добрым и достойным человеком. Она отличается своей народной мудростью, иронией и силой духа. Эта врождённая „духовная мощь” не соответствует её теперешней физической слабости, за которую ей действительно стыдно:

При Люсе старуха стыдилась себя, того, что она такая старая и слабая, ни кожи, ни рожи. Ей казалось, что и дочь тоже должна стыдиться её [...]. А что старуха видала в своей жизни? День да ночь, работу да сон. Вот и крутилась, будто белка в колесе, и все, кто жил с ней рядом, тоже крутились ничем не лучше, считая, что так и надо ${ }^{6}$.

В художественном изображении старости главной героини отмечается яркий конфликт между телом и душой. Как пишет Алла Большакова:

Ослабевшей героине принадлежит в повести лишь малая доля прямой речи причем ее высказывания, в основном, сведены к фиксации физиологических потребностей или относятся к ситуации ожидания приезда любимой дочери Таньчоры 7 .

Терпение и выносливость являются ключевыми элементами в характере и в мировосприятии Анны: как лейтмотивы эти качества постоянно сопровождают описание её личности. Неповторимый в своей колоритности разговор старухи с единственной подругой Миронихой позволяет читателю увидеть женщину в её потрясающе трудной, но чистой, честной и небезнадежной судьбе:

Нет, ей не страшно умереть, всему свое место. Хватит, нажилась, насмотрелась. Больше тратить в себе ей нечего, все истратила - пусто. Изжилась до самого донышка, выкипела до последней капельки. А что, спрашивается, видала она в своей жизни? Только одно и знала: ребятишки, которых надо было накормить, напоить, обстирать, загодя заготовить, чтобы было чем напоить, накормить их завтра. Восемьдесят годов, как видно, одному человеку все-таки много, если она поизносилась до того, что теперь только взять да выбросить, но, оглядываясь сейчас на них со своего смертного порога, она не находила между ними большой разницы - все они, подгоняя друг друга, прошли одинаково в спешке: по десять раз на дню старуха задирала в небо голову, чтобы посмотреть, где солнце, и спохватывалась - уже высоко, уже низко, а она все еще не поправилась с делами. Всегда одно и то же: теребили с чем-нибудь ребятишки, кричала скотина, ждал огород, а еще работа в поле, в лесу, в колхозе - вечная круговерть, в которой ей некогда было вздохнуть и оглядеться по сторонам, задержать в глазах и вдуше красоту земли и неба. «Скорей, скорей», — подгоняла она себя,

${ }^{5}$ О влиянии русских поминально-погребальных обрядов на изображение смерти в творчестве Распутина писала Александра Урбан-Подолян, Поминально-погребальные обряды в прозе Валентина Распутина, [в:] Поэтика быта. Русская литература XVIII-XXI вв., ред. А. Графа, Мюнхен 2014, с. 283-291.

${ }^{6}$ В. Распутин, Последний..., с. 146.

${ }^{7}$ А. Большакова, Русская деревенская проза..., с. 105. 
набрасываясь то на одно дело, то на другое, а им, сколько ни делай, не видно было ни конца и ни края. Вот так и пролетела вся жизнь, по годам вроде долгая, разная - вон сколько меры старуха взяла на себя, а по памяти бедная: одно находило на одно, год на год, забота на заботу ${ }^{8}$.

Как было уже отмечено, в отличие от типичных реакций пожилых персонажей в западной культурной традиции, старая женщина относится просто, почти естественно к своей приближающейся кончине. Она не боится, не цепляется за жизнь и спокойно готовится покинуть этот свет. В сущности, поведение Анны напоминает бытовую, лаконичную сцену смерти ямщика Фёдора в рассказе Три смерти Льва Толстого (1858). Здесь, как известно, этот „маленький”, тихий уход из жизни простого человека резко контрастирует с трагическим настроением умирающей госпожи Ширинской.

Альтруизм и чистота души распутинской Анны противопоставляются грубой черствости её детей, которые умеют только думать о себе и которые, очевидно, очень далеки от духовного мира матери. Прошлое и настоящее сосуществуют в сознании героини; через частое употребление несобственно-прямой речи Распутину удается показать поток сознания Анны ${ }^{9}$. Как заметила Дагмар Грамсгаммер-Гол ${ }^{10}$, в минуты просветления старуха посвоему размышляет над победой старости и над глубоким смыслом своего жизненного пути:

И только когда слегла, когда одолела старость, поопнулись и годы, заскрипели над её головой длинными сонными зимами - смотри, старуха, смотри и не говори, что год длиннее года, а у тебя их было довольно. Но она не жаловалась на свою жизнь, нет. Как можно жаловаться на то, что было твоим собственным, больше ничьим, и что выпало только тебе, больше никому? Как прошла, так и ладно, во второй раз не начнётся. Потому-то и хватает человеку одной жизни, что она у него одна, - двух бы не хватило. А старуха жила нехитро: рожала, работала, ненадолго падала перед новым днем в постель, снова вскакивала, старела — и все это там же, где родилась, никуда не отлучаясь, как дерево в лесу, и справляя те же человеческие надобности, что и ее мать ${ }^{11}$.

Восьмидесятилетняя старуха имеет ясное, чёткое представление о последнем этапе своего земного существования. Она последовательный человек. Родилась она и провела всю свою нехитрую жизнь в родной дерев-

${ }^{8}$ В. Распутин, Последний..., с. 158.

9 О стилистическом употреблении несобственно-прямой речи в прозе Распутина ср. В. Серафимова, Авторская идея в прозе В. Распутина и изобразительно-выразительные средства языка, „Русская словесность” 2009, № 1, с. 37-41 и I. Remonato, The shadow of time in Valentin Rasputin's writing: some observations on Free Indirect Discourse, [в:] Hовые направления в изучении лексикологии, словообразования и грамматики начала XXI века. Материаль международного симпозиума 4-5 мая 2009 года, Самара 2009, с. 219-225.

10 Об отношении Анны Степановны к старости см. D. Gramshammer-Hohl, Valentin Rasputin: Poslednyj srok, [в:] Repräsentationen weiblichen Alters in der russischen Literatur. Alt sein, Frau sein, eine alte Frau sein, „Grazer Studien zur Slawistik“, т. 5, Hamburg 2014, c. $176-177$.

11 В. Распутин, Последний..., с. 180. 
не, „как дерево в лесу”. Можно заметить подобные конкретные сравнения с природными элементами и в Прощзании с Матёрой. В образе старой женщины совестливость и честность сочетаются со смелостью и активностью. Она иронически относится к общепринятому мнению, что детство и старость схожи, хотя и разделяет его:

Смеются: старый да малый, имея в виду, что один выжил из ума, а второй его еще не нажил. Правильно, старый да малый - только они как следует и способны чутко и остро удивляться своему существованию, тому, что окружает их на каждом шагу ${ }^{12}$.

Перед лицом смерти, главная героиня долго вспоминает о прошлом, обо всей своей жизни, посвящённой семье и работе в деревне, и задаёт себе самый сокровенный, вечный вопрос: стоило ли жить?

Интересно, куда денется её жизнь? Ведь она жила, она помнит, что жила, это было совсем недавно. Кому достанется её жизнь, которую она, как работу, худо ли, хорошо ли довела до конца? Ну да, рукавички из неё не сошьешь - это правда. Помянут словом, кивнут в её сторону, и все - была и быльем поросла. А потом и поминать забудут. Тоже правда. А что ей ещё надо? Знать хотя бы, зачем и для чего она жила, топтала землю и скручивалась в верёвку, вынося на себе любой груз? Зачем? Только для себя или для какой-то пользы ещё? Кому, для какой забавы, для какого интереса она понадобилась? А оставила после себя другие жизни - хорошо это или плохо? Кто скажет? Кто просветит? Зачем? Выйдет ли из её жизни хоть капля полезного, жданного дождя, который прольется на жаждущее поле? ${ }^{13}$

Но Анна, прежде всего - мать, и только одна мысль волнует её в этот решительный час: иметь возможность снова увидеться и проститься как следует со своими детьми. Несмотря на материальность и нравственную отчуждённость их „городского” поколения, в глубине души Анна чувствует, что они всё равно „свои”. Видно, что для нее не представляется возможным развязать кровные узы. Как пишет Борис Панкин:

Во внутренних монологах Анны, в тех ее прерывных раздумьях, когда каждое суждение, каждая сценка словно омыты чистотой и бескорыстием последнего предсмертного чувства, мы слышим голос мудрости и доброты, который преодолевает условности и пути жанра, возвышается над обличительной направленностью сюжета ${ }^{14}$.

Как отметили многие критики, хронотоп сибирской деревушки тесно связан с психологическим обликом старухи ${ }^{15}$ : ведь она не могла бы даже и представить себе свою жизнь в другом крае.

12 Ibidem, c. 183.

13 Ibidem, c. 192.

${ }^{14}$ Б. Панкин, Прощъания и встречи с Матерой, [в:] idem, Строгая литература. Литературно-критические статьи и очерки, Москва 1980, с. 68.

15 О многослойности понятия и изображения времени в творчестве Распутина см., среди прочих, I. Remonato, Dallo spazio alla coscienza: il respiro del tempo nella scrittura di Valentin Rasputin, [в:] Immagini di tempo. Studi di Slavistica, ред. Р. Тоsco, Verona 2010, c. 179-194. 
Поэтическое изображение родных мест в Иркутской области, представляющих „малую родину” для автора-сибиряка, играет центральную роль и в повести Прощание с Матерой. Как известно, в тексте рассказывается о затоплении сибирского острова, вместе с одноимённой деревней, в связи со строительством гидроэлектростанции. Повествование, основанное на подлинных событиях в Забайкалье 1970-х годов, описывает последние, грустные недели существования этого замкнутого мира, приговорённого к исчезновению. Старики и старухи символически становятся единственными хранителями духовных ценностей и многолетних традиций деревенского микрокосма Матеры:

А постоянно оставались теперь в Матере только старики и старухи, они смотрели за огородом и домом, ходили за скотиной, возились с ребятишками, сохраняя во всем жилой дух и оберегая деревню от излишнего запустения. По вечерам они сходились вместе, негромко разговаривали — и всё об одном, о том, что будет, часто и тяжело вздыхали, опасливо поглядывая в сторону правого берега за Ангару, где строился большой новый посёлок ${ }^{16}$.

Пожилые жители острова олицетворяют уходящую в небытие гармонию. Речь идёт, прежде всего, о восьмидесятилетней старухе Дарье Пинигиной. В психологическом описании этой героини нет следов такой ригидности мышления, которая часто приписывается старикам и зачастую является причиной их трудной адаптации к новому положению. Старуха чувствует приближающийся конец. Для неё деятельность советского правительства противопоставляется естественному (т.е. божественному) порядку вещей. Она считается самой старой среди своих подруг, хотя ни одна из них не помнит своего возраста:

Старухи втроём сидели за самоваром [...] Сидели у Дарьи, самой старой из старух; лет своих в точности никто из них не знал, потому что точность эта осталась при крещении в церковных записях, которые потом куда-то увезли - концов не сыскать ${ }^{17}$.

В Дарье жива память о предках. Как верующая она уверена, что после смерти ей предстоит встреча с её покойными родными. Старая женщина отличается честностью, суровостью и здравым смыслом. Другие односельчане слушают и уважают её. Мысли и действия Дарьи отражают особое отношение человека и природы, которое было присуще в древней деревне и влияло на весь жизненный уклад её обитателей. Рассматривая голую местность полузаброшенного острова, главная героиня думает о прошлом, о старых, сельских предметах, вышедших из употребления и размышляет о пользе и смысле старости:

сколько, в самом деле, кругом старого, отслужившего свой век и службу, остающегося без надобности, но догнивающего медленно и неохотно. Как с ним быть? Что делать?

${ }^{16}$ В. Распутин, Прощание с Матерой, [в:] idem, Живи и помни. Повести. Рассказы, Москва 2002, с. 212.

17 Ibidem, c. 214. 
Тут ладно, тут все уйдет под огонь и воду, а как в других местах? И кажется Дарье: нет ничего несправедливей в свете, когда что-то, будь то дерево или человек, доживает до бесполезности, до того, что становится оно в тягость; что из многих и многих грехов, отпущенных миру для измоленья и искупленья, этот грех неподъемен. Дерево еще туда-сюда, оно упадет, сгниет и пойдет земле на удобрение. А человек? Годится ли он хоть для этого? Теперь и подкормку для полей везут из города, всю науку берут из книг, песни запоминают по радио. К чему тогда терпеть старость, если ничего, кроме неудобств и мучений, она не даёт? К чему искать какую-то особую, вышнюю правду и службу, когда вся правда в том, что проку от тебя нет сейчас и не будет потом, что все, для чего ты приходил в свет, ты давно сделал, а вся твоя теперешняя служба досаждать другим ${ }^{18}$.

Как уже упоминалось, слияние человека с природными элементами пронизывает всё творчество Распутина; отсюда вытекают наиболее показательные стилистические приёмы его письма. Перед нами встают образы, отражающие ментальность и простые рассуждения сибирских крестьян. Так же, как Анна Степановна в Последнем сроке, старики и старухи Матеры не могут себе представить ни жизни, ни смерти в другом месте. Они органично связаны со своей родной землей. Вот почему перед смертью этого мира они испытывают душевную боль, внутренний разлад. Откладывая отъезд со дня на день, Дарья и ее друзья так и не успевают покинуть остров. Объективно их ожидает поражение и гибель: „новый” советский образ жизни продвигается без них. Тем не менее, пожилые персонажи Матеры являются сильными, активными „победителями” на духовном и художественном уровнях, потому что их достоинство и последовательность превращают их в незабываемые литературные образы. На первый взгляд может показаться, что Распутин выступает против технического прогресса, против современных нравов и что он идеализирует патриархальность. На самом же деле, его отказ относится только к такому „бесчеловеческому” прогрессу, который не служит по-настоящему людям. Ведь символически старые герои противостоят не современности, а всему тому, что ведет к деградации в природе, обществе и человеке. Как отмечает Борис Панкин, „в повести Распутина во всеуслышание звучит другой голос - старухи Дарьи, ее соседок и подружек. Их слово в споре, где ставкой - вся прошлая и будущая их жизнь, их земля, верования, традиции, устои, - их слово, сказанное болью души, выстраданное всем опытом жизни, - весьма внушительно и впечатляюще"19.

Схоже представлен образ старости и в рассказе Василий и Василиса. Его герои, разведенные супруги, живут раздельно, в одиночестве. О пожилой героине мы узнаем в начале повести: она никому не доверяет и делает все сама, поздно ложится и рано встает ${ }^{20}$. Василиса верит в Бога и все время вздыхает: „Вздохи у неё имеют множество оттенков - от радости и удив-

18 Ibidem, c. 241-242.

19 Б. Панкин, Прощзания и встречи..., с. 77.

${ }^{20}$ С. Кривченко, Проблема одинокой старости в русской литературе второй половины ХХ века, „Уроки литературы” 2008, № 9, с. 13. 
ления до боли и страданий” 21 . Как у Дарьи Пинигиной, её день расписан не по часам, а по самоварам: „Первый самовар, второй, третий... На старости лет чаепитие заменяет ей чуть ли не все удовольствия" ${ }^{22}$. Причиной ее конфликта с мужем была потеря ребёнка, в которой был виноват пьяный Василий. Уже тридцать лет они живут в соседних домах, каждый день встречаются, но между ними потеряно взаимопонимание: „Будто не видят друг друга... и только каждый из них знает о присутствии другого"23. В качестве связующего элемента между ними автор представляет их сына Петра. Пётр - „среднее” между матерью и отцом. Он не любит тайгу, как Василий, и мать называет его „отиком”, хотя он не является неисправимым лентяем. Можно сказать, что образ Василисы собирает в себе бунтарский дух всех старых крестьянских жен. Она верующая, и, по нравственным правилам христианства, должна простить мужа. Василий же, осознав, что он наделал, поняв свою вину, в конце концов, понимает душевное состояние Василисы. А поняв это, ему уже нечего делать на этом свете, и он умирает. Распутин умело использует монологи для более полного раскрытия образов и метаморфоз героев. Например, Василиса в начале текста обращается к сыну ласково, по-матерински, а ближе к концу, когда Пётр принимает сторону отца и его новой жены, она относится к нему неласково, раздраженно. Старый Василий просит сына не продавать ружье, чтобы о нём осталась память; следовательно, он считает, что достоин того, чтобы о нем вспоминали. Писатель показывает, как в деревню пришли новые времена и новые возможности, а между тем деревня продолжает жить по старым законам ${ }^{24}$.

Духовным вопросам и конфликтному отношению между старыми и молодыми посвящено и одно из последних художественных произведений автора - рассказ Женский разговор, напечатанный в журнале „Москва" в 1995 году. В нём писатель показал встречу двух поколений: внучки и бабушки. Как известно, с нравственной точки зрения, Распутин является представителем традиционной классической литературы. В его понимании, любовь по-старинному соответствует целомудрию и милосердию. Поэтому заботиться, жалеть, отдавать, терпеть, сберегать, сохранять всё это - значит любить. В жизни бабушки Натальи заложены моральные ориентиры, по которым жили многие люди того времени. Можно заметить, что

${ }^{21}$ В. Распутин, Василий и Василиса, [в:] idem, Избранные произведения в 2-х томах, т. 2, Москва 1984, с. 391.

${ }^{22}$ Ibidem.

${ }^{23}$ Ibidem.

24 Советский художественный фильм по рассказу (Мосфильм 1981, режиссёр-постановщик Ирина Поплавская) точно и лирично показывает эту сцену. Об этом фильме см., в особенности, F. Björling, When the film is better than the book: Elem Klimov's "Farewell" and Valentin's Rasputin "Farewell to Matyora”, „Russian Studies in Literature”, № 3, 40, Summer 2004, c. 64-78. 
её внутреннее поведение является идеальным примером того, как нужно относиться друг к другу двум любящим сердцам.

Подводя итоги, можно отметить, что, в символическом плане, в образе распутинских старух, прежде всего матерей и бабушек, воплощаются умирающие духовные качества настоящей России. На уровне литературного изображения размышления и внутренние переживания героинь Распутина раскрывают их психологический облик, основанный на скромности, мудрости и на взаимоотношении с деревенской природой. В его произведениях старые люди являются хранителями моральных ценностей русского народа. В их портретах писатель воплотил образцы человеческого достоинства.

\section{Библиография}

Большакова А., Нация и менталитет: феномен «деревенской прозы» ХХ века, Москва 2000. Большакова А., Русская деревенская проза ХХ века: код прочтения, Шумен 2002.

Кривченко С., Проблема одинокой старости в русской литературе второй половины ХX века, „Уроки литературы” 2008, № 9.

Недзвецкий В., Филиппов В., Русская «деревенская проза», Москва 2002.

Панкин Б., Прощзания и встречи с Матерой, [в:] idem, Строгая литература. Литературнокритические статьи и очерки, Москва 1980.

Распутин В., Василий и Василиса, [в:] idem, Избранные произведения в 2-х томах, т. 2, Москва 1984.

Распутин В., Последний срок, [в:] idem, Избранные произведения в 2-х томах, т. 1, Москва 1984.

Распутин В., Прощуание с Матерой, [в:] idem, Живи и помни. Повести. Рассказы, Москва 2002 .

Серафимова В., Авторская идея в прозе В. Распутина и изобразительно-выразительные средства языка, „Русская словесность” 2009, № 1.

Урбан-Подолян А., Поминально-погребальные обряды в прозе Валентина Распутина, [в:] Поэтика быта. Русская литература XVIII-XXI вв., ред. А. Графа, Мюнхен 2014.

Augé M., Une ethnologie de soi. Le temps sans âge, Paris 2014.

Björling F., When the film is better than the book: Elem Klimov's "Farewell" and Valentin's Rasputin "Farewell to Matyora”, „Russian Studies in Literature”, № 3, 40, Summer 2004.

Gramshammer-Hohl D., Valentin Rasputin: Poslednyj srok, [в:] Repräsentationen weiblichen Alters in der russischen Literatur. Alt sein, Frau sein, eine alte Frau sein, „Grazer Studien zur Slawistik“, т. 5, Hamburg 2014.

Remonato I., Dallo spazio alla coscienza: il respiro del tempo nella scrittura di Valentin Rasputin, [в:] Immagini di tempo. Studi di Slavistica, ред. Р. Тоsco, Verona 2010.

Remonato I., The shadow of time in Valentin Rasputin's writing: some observations on Free Indirect Discourse, [в:] Новые направления в изучении лексикологии, словообразования и грамматики начала ХХІ века. Материаль международного симпозиума 4-5 мая 2009 года, Самара 2009.

Spedicato Iengo E., Senilità e dintorni, Lanciano 2003.

Tramma S., Inventare la vecchiaia, Roma 2000. 


\section{Some observations regarding the image of old age in Valentin Rasputin's work}

\section{Summary}

The present essay is devoted to images of old age in the work of the Russian writer Valentin Rasputin (1937-2015). The artistic representation of aging plays a meaningful role in the poetics of the Siberian author, and the thick, transversal presence of the motive gives us the opportunity to examine the different modes it is described in the texts. The old villagers' figures are analyzed on the background of the peculiar chronotope in which they live, organically connected to wild Siberian nature. The study focuses in particular on the psychological portraits of old characters in the novels Poslednyj srok (The Last Term, 1970) and Proščanie s Matëroj (Farewell to Matyora, 1976). In the second part of the paper are proposed some thematic parallels with old charakters' images present in the short stories Vasilij i Vasilisa (Vasili and Vasilissa, 1966) and Ženskij razgovor (Women's Dialogue, 1995), in which the psychological portraits and the atmosphere appear similar.

Keywords: Valentin Rasputin, old peasant women, life, death, nature, memory

\section{O obrazie starości w twórczości Walentina Rasputina uwag kilka}

\section{Streszczenie}

W artykule omówiony został obraz starości w twórczości prozatorskiej Walentina Rasputina (1937-2015). Autorka udowadnia, że obraz ten zajmuje ważne miejsce w świecie przedstawionym wykreowanym przez syberyjskiego pisarza. To właśnie ciągłość i stała obecność tego motywu w utworach Rasputina umożliwia analizę różnorodnych aspektów i odcieni znaczeniowych starości. Stworzone przez pisarza postaci starych ludzi rozpatrywane i analizowane są w ich stosunku do przyrody syberyjskiej oraz chronotopu, w którym są umiejscowione. W centrum działań analitycznych autorki artykułu znajduje się charakterystyka duchowa i psychologiczna starych ludzi, przedstawionych przez Rasputina w utworach Последний срок (W ostatnia godzinę, 1970) і Прощяание с Матерой (Pożegnanie z Matiora, 1976). Przeprowadzone zostały także paralele z opowiadaniami Василий и Василиса (Wasilij i Wasilisa, 1966) oraz Женский разговор (Kobieca rozmowa, 1995).

Słowa kluczowe: Walentin Rasputin, stare kobiety, życie, śmierć, przyroda, pamięć 